\title{
Eosinophilic pneumonia as a presentation of occult chronic granulomatous disease
}

\author{
D. Trawick*, A. Kotch+, R. Matthay*, R.J. Homer**
}

\begin{abstract}
Eosinophilic pneumonia as a presentation of occult chronic granulomatous disease. D. Trawick, A. Kotch, R. Matthay, R.J. Homer. (CERS Journals Ltd 1997.

ABSTRACT: We present a case of invasive pulmonary aspergillosis (IPA) in a previously healthy young woman who presented with what initially appeared to be an acute eosinophilic pneumonia. A second lung biopsy taken after treatment with steroids showed invasive Aspergillus with associated necrotizing granulomas, a pattern commonly found in chronic granulomatous disease (CGD). Both siblings, and by extrapolation, the patient, were actually found to have CGD. A review of the literature revealed other cases of presumed immunocompetent patients with IPA with presentations and lung histopathology similar to that of our patient.

We conclude that chronic granulomatous disease presenting in the adult may be more common than previously assumed, and that patients previously presumed immunocompetent, but with granulomatous invasive pulmonary aspergillosis, may have chronic granulomatous disease. Furthermore, and most devastatingly in this case, the presentation may simulate a recently described steroid responsive acute lung disease, acute eosinophilic pneumonia.
\end{abstract}

Eur Respir J 1997; 10: 2166-2170.

Chronic granulomatous disease (CGD) in the adult may be more common than previously assumed $[1,2]$. We report the case of a previously healthy young woman who developed a fulminate invasive pulmonary aspergillosis (IPA) after presenting with what was initially thought to be an acute eosinophilic pneumonia (AEP) [3-6]. The histology of her IPA revealed parenchymal necrotizing granulomas with identifiable hyphae, a histological pattern of IPA described primarily in CGD [7, 8]. Subsequent immunological analysis revealed that both adult siblings, and by extrapolation the patient, had an autosomal recessive form of CGD. A review of the literature disclosed other presumed immunocompetent patients who, generally after massive exposure, and in the same manner as our patient, initially presented with eosinophilia, often associated with hyperimmunoglobulinaemia E (hyper-IgE), and then simultaneously or subsequently developed IPA with suppurative necrotizing granulomas. Some of these patients were tested for CGD using the nitroblue tetrazolium (NBT) test. However, recent evidence shows that a normal NBT test does not rule out CGD [1]. This case and those reviewed here underscore that CGD can present in the adult and that patients with IPA who were presumed immunocompetent may actually have had CGD. Furthermore, their presentation simulates that of a different recently described acute lung disease, AEP [3-6].

\section{Case report}

A white female aged 23 yrs developed sudden onset of dyspnoea, dry cough and fever approximately $12 \mathrm{~h}$

\begin{abstract}
* Section of Pulmonary and Critical Care Medicine, Yale University School of Medicine, and the **Dept of Pathology, Yale University School of Medicine and Pathology and Laboratory Medicine Service, VA Connecticut Healthcare System, West Haven, CT, 06517, New Haven, Connecticut. +Pulmonary and Critical Care Medicine, Danbury Hospital, Danbury Connecticut, USA.

Correspondence: D.R. Trawick, Pulmonary and Critical Care Medicine, University of Rochester School of Medicine and Dentistry, Strong Memorial Hospital, 601 Elmwood Avenue, Box 692, Rochester, NY 14642, USA

Keywords: Acute eosinophilic pneumonia chronic granulomatous disease invasive pulmonary aspergillosis Received: November 71996 Accepted after revision May 11997
\end{abstract}

after working in a yard with compost on July 3, 1994. She was seen in consultation by a pulmonologist after 2 days of persistent symptoms. When she presented to the office she was febrile to $38.3^{\circ} \mathrm{C}\left(101^{\circ} \mathrm{F}\right)$. Her physical examination was significant for bibasilar rales. A complete blood count $(\mathrm{CBC})$ revealed a white blood count (WBC) of 13,000 cells $\mu \mathrm{L}^{-1}$ with $10 \%$ eosinophils. Her room air oximetry was $93 \%$ but dropped to $87 \%$ with walking. Her chest radiograph revealed diffuse bilateral alveolar infiltrates (fig. 1). The patient was immediately

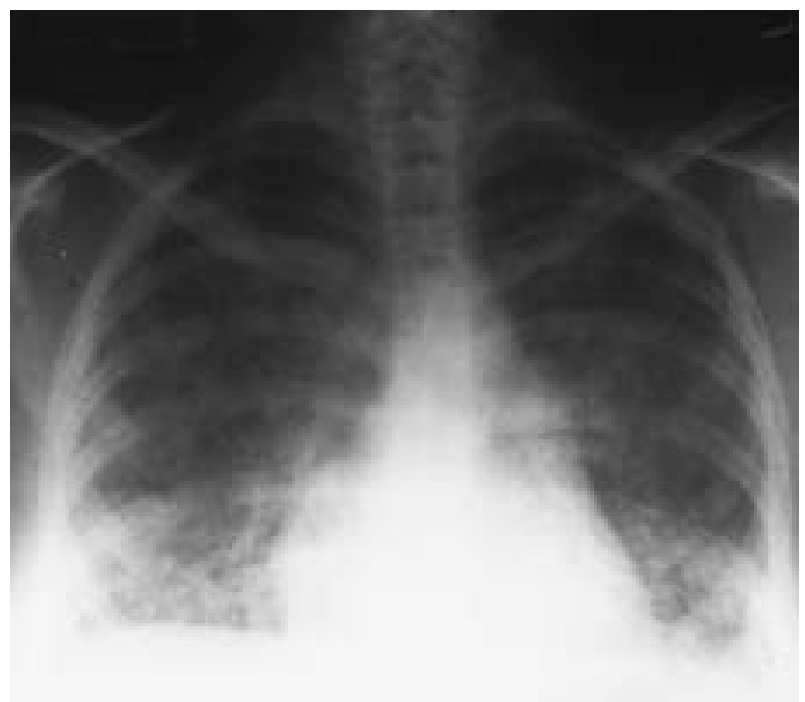

Fig. 1. - Chest radiograph from July 5 1994, on presentation to Danbury Hospital, 2 days after working in the compost pile. Bilateral infiltrates are noted. 
admitted to hospital and underwent bronchoscopy. The airways were unremarkable. The bronchoalveolar lavage (BAL) differential revealed $67 \%$ eosinophils. A transbronchial biopsy demonstrated a well-preserved alveolar architecture with extensive eosinophilic infiltration. No granulomas were seen. Grocott-methanamine stains for fungus were negative. Gram stain, bacterial cultures, fungal and acid-fast bacillus (AFB) smears and cultures on both BAL fluid and the transbronchial biopsy specimens were negative. Her erythrocyte sedimentation rate (ESR) was $130 \mathrm{~mm} \cdot \mathrm{h}^{-1}$. A hypersensitivity pneumonitis screen revealed positive precipitins for Aspergillus niger and A. flavus. Her serum immunoglobulin (Ig) E levels were greater than 5,000 (normal range 15-40) international units (IU) $\cdot \mathrm{mL}^{-1}$. The differential diagnosis included AEP vs hypersensitivity pneumonitis. The patient was begun on $40 \mathrm{mg}$ of i.v. methylprednisolone every $6 \mathrm{~h}$. Within $24 \mathrm{~h}$ she had defervesced, her room air oximetry improved from 86 to $90 \%$, and her chest radiograph exhibited significant improvement (fig. 2). She was discharged on $60 \mathrm{mg}$ of prednisone.day ${ }^{-1}$ after 3 days in the hospital.

Her medical history was significant for childhood recurrent furunculoses and hyper-IgE (200-5,000 IU $\left.\cdot \mathrm{mL}^{-1}\right)$ beginning at age 4 yrs. Immunological examination revealed no specific diagnosis, although the possibility of Job's syndrome, or a variant, had been entertained. The infections cleared when treated with dicloxacillin but promptly recurred when the drug was discontinued. The patient was placed on chronic dicloxacillin until age 10 yrs and thereafter remained asymptomatic on no medication. From ages 10-23 yrs, the patient remained very healthy and was visiting her family in Connecticut while on summer vacation from her medical school in Grenada. She had no history of smoking, previous pneumonias or asthma, or exercise intolerance. There was no history of intravenous drug abuse and she had no human immunodeficiency virus (HIV) risk factors. She was on no medication at the time of presentation.

The patient was seen in follow-up on July 121994 , 1 week after starting corticosteroid treatment and reported feeling well. She was afebrile and her physical exam was unchanged. A repeat chest radiograph on July 14

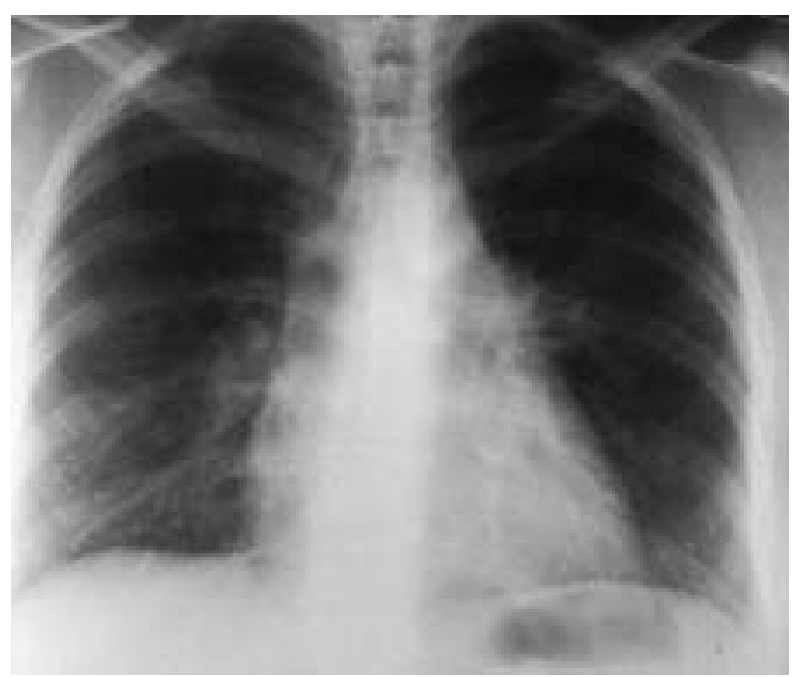

Fig. 2. - Chest radiograph from July 7 1994. Note significant clearing of infiltrates.
1994 revealed decreased but persistent infiltrates. A reduction of her prednisone was begun but she developed a fever, recurrent dry cough, and dyspnoea. A diagnosis of tropical eosinophilia was entertained but stool cultures and smears were negative, as were microfilarial titers. She was placed back on her original dose of $60 \mathrm{mg}$ prednisone $\cdot \mathrm{day}^{-1}$ but her symptoms persisted. A chest radiograph on July 251994 revealed worsened infiltrates with a nodular appearance. Open lung biopsy was discussed with the patient but she deferred at the time. Her steroid dose was increased to $120 \mathrm{mg}$ prednisone. ay $^{-1}$ and then changed to methylprednisolone and her symptoms improved. A repeat chest radiograph on August 31994 revealed further progression of her infiltrates (fig. 3). A chest computed tomography (CT) scan on August 41994 revealed diffuse interstitial and nodular alveolar infiltrates with confluence (fig. 4). A sputum culture from August 11994 revealed Aspergillus fumigatus.

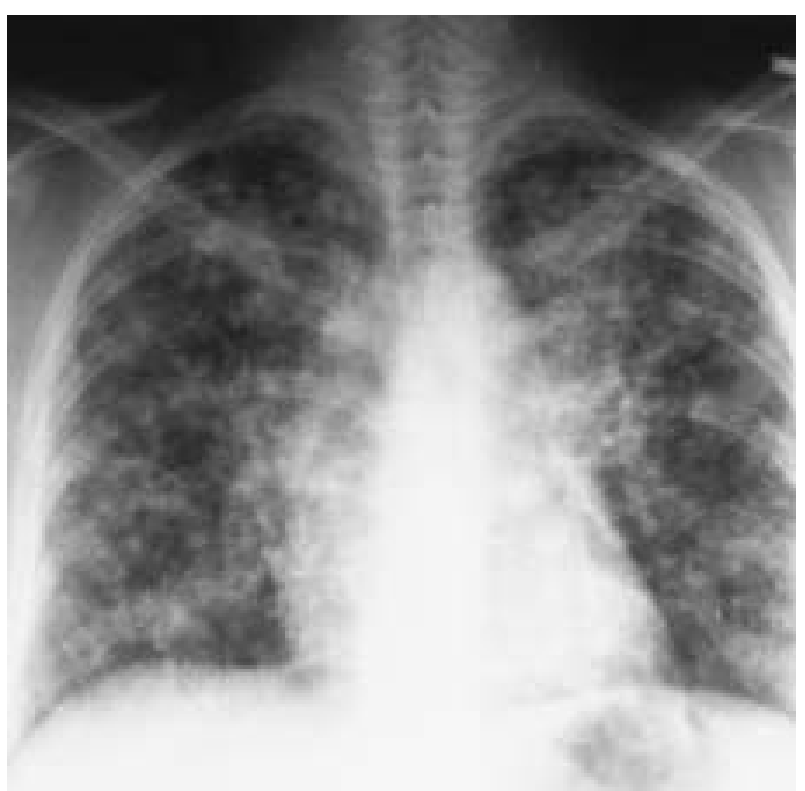

Fig. 3. - Chest radiograph on August 31994 revealing worsening bilateral infiltrates, despite prednisone, now with a moderate nodular appearance.

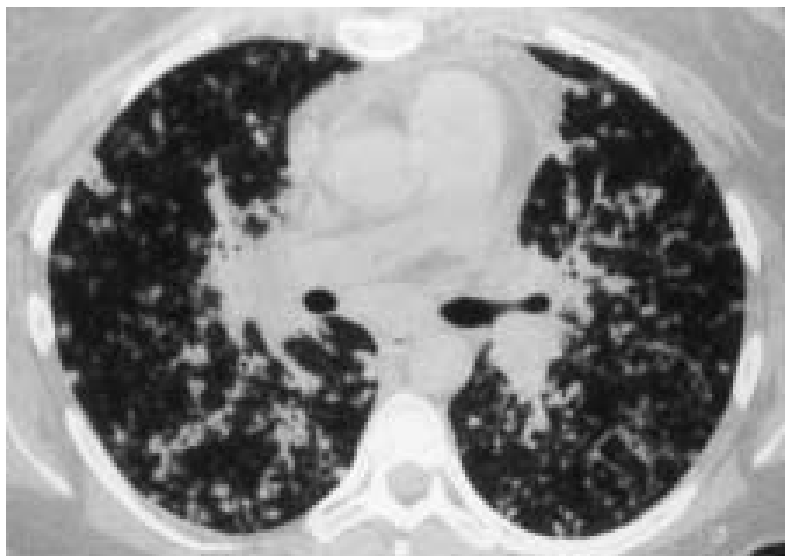

Fig. 4. - Computed tomography scan of chest performed on August 41994 revealing diffuse interstitial and alveolar infiltrates with confluence. 
The patient was admitted to the Yale New Haven Hospital (YNHH) for thoracoscopic open lung biopsy on August 6 1994. On admission she was alert without apparent distress. Her temperature was $38.9^{\circ} \mathrm{C}$, respiratory rate 22 breaths $\cdot \mathrm{min}^{-1}$, cardiac frequency 140 beats. $\mathrm{min}^{-1}$, and blood pressure $120 / 70 \mathrm{mmHg}$. The $\mathrm{CBC}$ revealed a WBC of 13,700 cells $\mu \mathrm{L}^{-1}$ with $77 \%$ segmented neutrophils, $18 \%$ bands and $0 \%$ eosinophils. Her room air arterial blood gas (ABG) was $\mathrm{pH} 7.51$, partial pressure of carbon dioxide $\left(\mathrm{PCO}_{2}\right) 4.9 \mathrm{kPa}(37 \mathrm{mmHg})$, partial pressure of oxygen $\left(\mathrm{PO}_{2}\right) 10.9 \mathrm{kPa}(82 \mathrm{mmHg})$, and $97 \%$ haemoglobin saturation. Blood and sputum cultures were obtained and she was begun on amphotericin B (0.6 $\mathrm{mg} \cdot \mathrm{kg}^{-1}$ after a test dose) and oxacillin. The thoracoscopic examination on August 71994 revealed a diffusely diseased and fibrotic right lung with multiple small nodules. Histology (figs. 5 and 6) showed necrotizing suppurative granulomas with septate hyphae throughout the parenchyma. Most of the granulomas were not centred on either bronchioles or vessels although on silver stain, rare bronchioles did have identifiable hyphae within them. This was confirmed by elastic stains to highlight vessels and bronchi. The amphotericin B was increased to $1.0 \mathrm{mg} \cdot \mathrm{kg}^{-1}$. On August 81994 the patient developed worsening infiltrates, episodes of hypotension, and hypoxaemia. She developed progressive hypoxaemia and

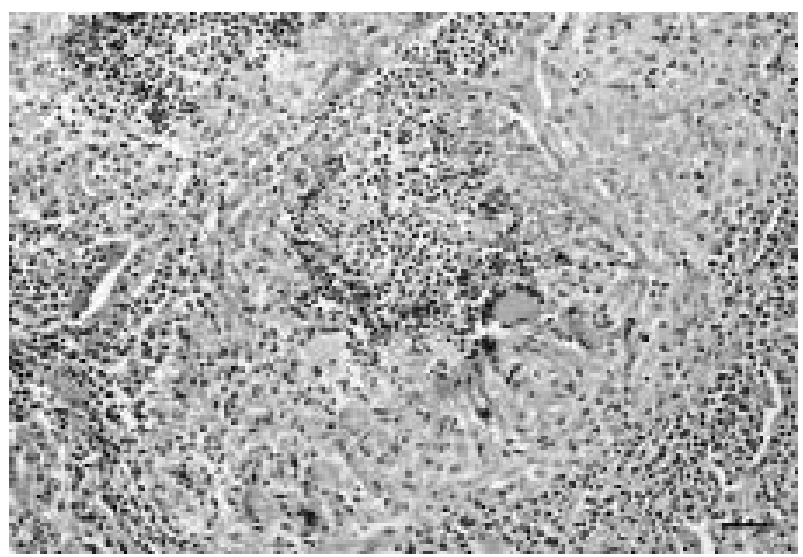

Fig. 5. - Thoracoscopic lung biopsy showing epithelioid granulomas with giant cells. In the centre of the granuloma is suppurative inflammation with neutrophils and debris. Haematoxylin and eosin stain. Internal scale bar $=100 \mu \mathrm{M}$.

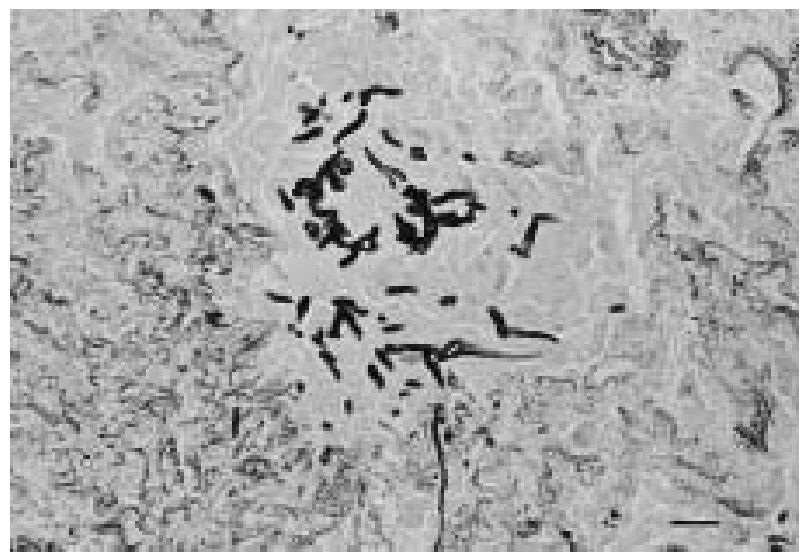

Fig. 6. - Fungal stain showing branching hyphae consistent with Aspergillus sp. in centre of granuloma. Grocott-methanamine stain. Internal scale bar $=30 \mu \mathrm{M}$. hypercapnoea and died early in the morning of August 10 1994. No autopsy was performed.

One year later, the patient's 17 yr old sister presented with cough, fever, and general malaise. A chest radiograph revealed a cavitary right upper lobe cavitary lesion with an air-fluid level as well as an ill-defined infiltrate in the right middle lobe. She was placed on clindamycin for presumed aspiration pneumonia and her WBC fell from 12,000 to 8,000 cells $\mu \mathrm{L}^{-1}$. She and her $21 \mathrm{yr}$ old brother were subsequently tested for NBT and superoxide generation at the Mount Sinai Medical Center in New York city. Neither had any superoxide hyperglobulinaemia and the NBT test showed no reduction. Her brother showed a modest hyperglobulinaemia with an $\operatorname{IgG}$ of $1761, \operatorname{IgA}$ of 260 , IgM 43, and $\operatorname{IgE}$ of $2554 \mathrm{IU} \cdot \mathrm{mL}^{-1}$. Both siblings, and by extrapolation, the deceased sister, were diagnosed with an autosomal recessive form of CGD. Both siblings of the patient are now on trimethoprim/sulfamethoxazole DS b.i.d. and are receiving subcutaneous injections of gamma interferon $50 \mathrm{mg} \cdot \mathrm{m}^{-2}$ three times weekly.

\section{Discussion}

The case described above depicts IPA in an adult with CGD who was previously assumed immunocompetent. The features of this patient's presentation and her course are similar to other cases in the literature in which presumed immunocompetent individuals initially present with hyper-IgE, eosinophilia (of blood, tissue, or BAL), often after massive exposure and then, either simultaneously or subsequently, develop an IPA characterized by suppurative granulomas within the parenchyma of the lung [9-14].

The salient features of these similar cases extracted from the literature are summarized below and in table 1. RICKER et al. [9] described a case similar to ours in which an $11 \mathrm{yr}$ old boy presented with cough and infiltrates $8 \mathrm{~h}$ after playing in a compost pile. Acute eosinophilic pneumonia was diagnosed by BAL. No bacteria, fungi, or viruses grew from blood or BAL cultures. Corticosteroid therapy was begun resulting in immediate improvement and he was discharged on the eighth hospital day only to return 3 days later with fever, tachypnoea and worsening infiltrates on chest radiograph. Open lung biopsy revealed necrotizing granulomas with septate branching hyphae and subsequent autopsy revealed nearly confluent granulomas containing fungal hyphae. Aspergillus fumigatus was cultured from both BAL fluid and lung. A NBT test was reported as normal.

Meener et al. [12] described the outcome of two brothers, aged 32 and 19 yrs, who both developed low grade fevers and chills within 2 weeks after unrolling $1 \mathrm{yr}$ old hay. Both presented with interstitial nodular infiltrates. BAL from the older brother demonstrated no organisms on smear, remained culture negative, and revealed only $3 \%$ eosinophils on the differential. $\mathrm{He}$ exhibited spontaneous improvement both symptomatically and radiographically over 2 weeks. Bronchoscopy with BAL performed on the younger brother revealed 34\% eosinophils and open lung biopsy demonstrated suppurative-type granulomas with hyphae characteristic of Aspergillus spp. 
Table 1. - Summary of cases discussed within the text

\begin{tabular}{|c|c|c|c|c|c|c|c|}
\hline Reference & $\begin{array}{l}\text { Suppurative } \\
\text { granuloma }\end{array}$ & $\begin{array}{l}\text { Increased } \\
\text { IgE }\end{array}$ & $\begin{array}{l}\text { Eosinophilia } \\
\text { (tissue) }^{\S}\end{array}$ & $\begin{array}{l}\text { Eosinophilia } \\
\text { (blood) }\end{array}$ & $\begin{array}{l}\text { Eosinophilia } \\
\text { (BAL) }\end{array}$ & $\begin{array}{l}\text { Massive } \\
\text { exposure }\end{array}$ & $\begin{array}{l}\text { Post- } \\
\text { steroids }\end{array}$ \\
\hline RicKer et al. [9] & Yes & No & Yes* & $\begin{array}{c}\text { Yes } \\
\text { WBC }=15 \\
8 \% \text { Eos }\end{array}$ & $\begin{array}{c}\text { Yes }^{\#} \\
27 \% \text { Eos }\end{array}$ & Yes & Yes \\
\hline COOPER et al. [11] & Yes & $\begin{array}{c}\text { Yes } \\
3667 \\
(10-506)\end{array}$ & NA & $\begin{array}{c}\text { Yes } \\
\text { WBC }=10.6 \\
19 \% \text { Eos }\end{array}$ & NA & No & No \\
\hline MEEKER et al. [12] & Yes & $\begin{array}{l}\text { Yes } \\
6630 \\
(0-260)\end{array}$ & Yes** & $\begin{array}{c}\text { Yes } \\
\text { WBC=21.7 } \\
7 \% \text { Eos }\end{array}$ & $\begin{array}{c}\text { Yes }^{\dagger} \\
34 \% \text { Eos }\end{array}$ & Yes & No \\
\hline Yocum et al. [13] & Yes & $\begin{array}{c}\text { Yes } \\
1300 \\
(0-90)\end{array}$ & Yes $^{+}$ & No & NA & Yes & No \\
\hline ZuK et al. [14] & Yes & NA & No & No & No & Yes & Yes \\
\hline
\end{tabular}

*: open lung biopsy revealed granuloma with necrotic centres containing eosinophils and neutrophils; **: open lung biopsy revealed suppurative-type granuloma containing hyphae characteristic of Aspergillus spp. with "prominent" eosinophilia; +: transbronchial biopsy revealed consolidation of parenchyma with infiltrates of plasma cells, lymphocytes, and a "moderate number" of eosinophils. Numerous granulomas were seen with focal areas of central necrosis containing leucocytes, eosinophils, and necrotic debris; $\ddagger$ : WBC reported as $10^{3}$ cells $\mu \mathrm{L}^{-1}$; \#: Total cell count in the BAL was $18 \times 10^{6}$ in $24 \mathrm{~mL}$; the BAL was 561 cells $\cdot \mu \mathrm{L}^{-1}$; $\S$ : values are reported as Units· $\mathrm{mL}^{-1}$. Normal values for the reporting laboratory given in parentheses. NA: not applicable (not addressed within the cited paper); BAL: bronchoalveolar lavage; IgE: immunoglobulin E; WBC: white blood cell count; Eos: eosinophils.

Yocum et al. [13] described a case of a $37 \mathrm{yr}$ old woman who developed persistent fever, malaise, and dry cough after bagging mouldy oats. On presentation 3 weeks later she was noted to have bilateral miliary interstitial fibronodular infiltrates. A transbronchial biopsy of the lower lobe of the lung revealed consolidation of the parenchyma with an infiltration of plasma cells, lymphocytes, and a "moderate number" of eosinophils. Numerous granulomas were identified throughout the lobule with branching septate hyphae characteristic of Aspergillus fumigatus within the necrotic centres of the granulomas. Aspergillus fumigatus was cultured from the BAL. The patient received 6 days of antituberculous therapy. Her temperature began to diminish, but after the results of her bronchoscopy were known, the medications were discontinued and her fever did not recur. While reported as a hypersensitivity reaction, the histology is not consistent with that interpretation, but rather, in conjunction with the history, indicates a selflimited infection.

COOPER et al. [11] described the case of a $33 \mathrm{yr}$ old man who developed IPA of both the pericardium and lung. No discernible immunological defects were detected despite extensive testing. Biopsy specimens from his lung showed "granuloma" formation.

Finally, Zuk et al. [14] reported the case of a previously healthy gardener aged 34 yrs who presented with a 5 day history of dry cough, fever, and dyspnoea. A chest radiograph revealed bilateral basal infiltrates. A bronchoscopy on day 7 of his hospitalization failed to demonstrate organisms. His condition deteriorated and at autopsy his lungs were diffusely involved with suppurative granulomas with giant cells. Fungal hyphae were present within the giant cells.

Two important questions are generated by the comparison of our case to those described. Firstly, did any of these presumably immunocompetent patients with IPA actually have CGD? Although some of these patients were acutely treated with steroids, and cases of invasive aspergillosis developing after steroid therapy de novo or for hypersensitivity-related Aspergillus disease are certainly well-described (if uncommon, especially after short courses of steroids), most of the patients described herein did not require steroids for invasion. In addition, every one of these patients had suppurative granulomas as a response to the Aspergillus invasion. The histopathology of this form of IPA has been described commonly only for CGD in which Aspergillus bronchopneumonia has been noted with some frequency [8, 15, 16]. Kelly et al. [8], in a retrospective examination of IPA in patients without major risk factors, suggested that Aspergillus bronchopneumonia with suppurating granulomas is sufficiently distinctive to suggest CGD when no other risk factor is present. Although most cases of CGD are manifest before age $3 \mathrm{yrs}$, a recent retrospective analysis suggests that CGD first presenting in adults may be more common than previously assumed [1]. In that study, four of the 11 patients with CGD had a normal or near normal NBT test. Diagnosis was possible only on quantitative measurement of superoxide production in the granulocytes. Of note, two of the 11 patients died from complications of the CGD, one at age 23 yrs (the same age as our patient) after contracting a fulminate Aspergillus pneumonia.

The second question generated by our case is whether Aspergillus is at least one of the undefined antigens responsible for AEP. Our patient, on initial presentation, fulfilled essentially all the diagnostic criteria of ALLEN et al. [5] for AEP. However, she now represents at least the second case in the literature of an individual presenting with what appeared to be an AEP who subsequently developed a fatal IPA after initial improvement with glucocorticoids [9]. Her IPA could be attributed to her underlying CGD and the massive inhalation of spores from working in the compost pile. IPA is a common complication of CGD and can occur in these patients after massive exposure to spores from sources such as hay and marijuana. The corticosteroids she was given for the presumed AEP probably accelerated her course.

These cases suggest a common overall pattern associating massive exposure to Aspergillus spp., a hypersensitivity response with eosinophilia, and the development 
of IPA with necrotizing suppurative granulomas. We propose that: 1) previously reported cases of invasive pulmonary aspergillosis in presumed immunocompetent adults may have been, in fact, invasive pulmonary aspergillosis in adults with chronic granulomatous disease; 2) Aspergillus species may represent at least one of the so far unidentified antigens responsible for acute eosinophilic pneumonia; and 3) acute eosinophilic pneumonia is, by definition, a diagnosis of exclusion, and infectious aetiologies, especially (but not exclusively) fungal, should be continuously pursued after corticosteroid treatment is initiated.

\section{References}

1. Liese J, Jendrossek V, Jansson A, et al. Chronic granulomatous disease in adults. Lancet 1996; 347: 220-223.

2. Schapiro B, Newburger P, Klempner M, Dinauer M. Chronic granulomatous disease presenting in a 69 year old man. N Engl J Med 1991; 325(25): 1786-1790.

3. Badesch D, King T, Schwarz M. Acute eosinophilic pneumonia: a hypersensitivity phenomenon? Am Rev Respir Dis 1989; 139: 249-252.

4. Buchheit J, Eid N, Rodgers G, Feger T, Yakoub O. Acute eosinophilic pneumonia with respiratory failure: a new syndrome? Am Rev Respir Dis 1992; 145: 716718 .

5. Allen J, Davis W. Eosinophilic lung disease. Am J Respir Crit Care Med 1994; 150: 1423-1438.

6. Allen J, Pacht E, Gadek J, Davis W. Acute eosinophilic pneumonia as a reversible cause of noninfectious respiratory failure. $N$ Engl J Med 1989; 321: 569-574.

7. Moskaluk C, Pogrebniak H, Pass H, Gallin J, Travis W. Surgical pathology of the lung in chronic granulomatous disease. Am J Clin Pathol 1994; 102: 684-691.
8. Kelly J, Pinto A, Whitelaw W, Rorstad O, Bowen T, Matheson D. Fatal Aspergillus pneumonia in chronic granulomatous disease. Am J Clin Pathol 1986; 86: 235-240.

9. Ricker DH, Taylor SR, Gartner JC Jr, Kurland G. Fatal pulmonary aspergillosis presenting as acute eosinophilic pneumonia in a previously healthy child. Chest 1991; 100: 875-877.

10. Rodenhuis S, Beaumont F, Kaufmann HF, Sluiter HJ. Invasive pulmonary aspergillosis in a nonimmunosuppressed patient: successful managment with systemic amphotericin and flucytosien and inhaled amphotericin. Thorax 1984; 39: 78-79.

11. Cooper JAD, Weinbaum DL, Aldrich TK, Mandell GL. Invasive aspergillosis of the lung and pericardium in a nonimmunocompromised 33 year old man. Am J Med 1981; 71: 903-907.

12. Meeker DP, Gephardt GN, Cordasco EM Jr, Wiedemann HP. Hypersensitivity pneumonitis versus invasive pulmonary aspergillosis: two cases with unusual pathologic findings and review of the literature. Am Rev Respir Dis 1991; 143: 431-436.

13. Yocum MW, Saltzman AR, Strong DM, et al. Extrinsic allergic alveolitis after Aspergillus fumigatus inhalation: evidence of a type IV immunologic pathogenesis. Am J Med 1976; 61: 939-945.

14. Zuk J, King D, Zakhour H, Delaney J. Locally invasive pulmonary aspergillosis occurring in a gardener: an occupational hazard? Thorax 1989; 44: 678-679.

15. Conrad D, Warnock M, Blanc P, Cowan M, Golden J. Microgranulomatous aspergillosis after shoveling wood chips: report of a fatal outcome in a patient with chronic granulomatous disease. Am J Indust Med 1992; 22: 411-418.

16. Babior B, Woodman R. Chronic granulomatous disease. Semin Hematol 1990; 27: 247-259. 